\title{
A case of Plus minus lid syndrome with Hypesthesia-Hemiataxia
}

\author{
Sinjan Ghosh ${ }^{1}$, Gautam Guha ${ }^{2}$ Manoj Kumar Roy ${ }^{3}$, Annesh Bhattacharjee ${ }^{4}$, \\ Nikhil Repaka ${ }^{5}$, Sourav Nanda ${ }^{6}$, Niraja Agasti ${ }^{7}$ \\ ${ }^{1,3}$ Post DM Senior Resident, $, 5,5,6,7$ DM Resident, ${ }^{2}$ Associate Professor, Department of Neurology, Nil Ratan Sircar \\ Medical College and Hospital, Kolkata, West Bengal, India
}

\section{A B S T R A C T}

We present the case of a patient with paramedian mesencephalic and ipsilateral thalamic infarction with an unusual clinical presentation, where the diagnosis and accurate anatomical localization were imperative for a unique clinicoradiological correlation. Our patient was a 42-years old, right-handed Indian gentleman with hypertension who presented following acute myocardial infarction. He developed acute diplopia, left ptosis and right eyelid retraction. There was an associated hemiataxia and diminished sensation in right half of body. Plus-minus lid syndrome andhemiataxia -hypesthesia are two different clinical syndromes. A co-association of these two syndromes in the same patient is rare which was evident in our case.

Key words: Plusminus; Hypesthesia; ptosis; lid retraction; midbrain infarction; Hemiataxia

Access this article online

Website:

http://nepjol.info/index.php/AJMS

DOI: 10.3126/ajms.v11i3.28305

E-ISSN: 2091-0576

P-ISSN: 2467-9100

Copyright (c) 2020 Asian Journal of Medical Sciences

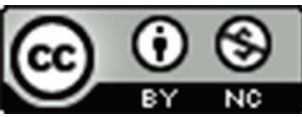

This work is licensed under a Creative Commons Attribution-NonCommercial 4.0 International License.

\section{INTRODUCTION}

Plus minus lid syndrome is an acquired neurological abnormality of eyelid position, which concerns the association of unilateral ptosis with contralateral eyelid retraction. ${ }^{1}$

This association has been described in ocular myasthenia, after lesions of oculomotor nerve, ocular myositis and paramedian mesencephalic-diencephalic lesions. Contralateral retraction may also occur as a mechanical effect secondary to ipsilateral ptosis (Hering's Law).In such cases on raising the ptotic lid manually the contralateral retraction corrects itself. ${ }^{2}$

A hypesthesia-hemiataxia syndrome has been described in contralateral thalamic lesions attributed to the VPL nucleus in the thalamogeniculate territory. ${ }^{3}$
This case reiterates the importance of clinical application of the neuroanatomical knowledge and interpretation of rare presentations of mesencephalic strokes.

\section{CASE REPORT}

A 42 yrs old right handed Indian male, hypertensive, smoker presented with Acute myocardial infarction. He was on Aspirin (75mg), Clopidogrel (75mg), Atorvastatin (40mg) Ramipril (5mg), Metoprolol (25mg) and Nitrates.

Two days later he developed a sudden onset right hemiparesis, right hypesthesia with gait imbalance and a tendency to fall towards right. He had associated binocular horizontal diplopia in right lateral gaze and complete ptosis of left eye.

On Physical examination he had stable vitals with normal higher mental functions. Cranial nerve examination revealed 
a complete ptosis in the left eye and exotropia with upper lid retraction of right eye and right superior rectus weakness, leaving a white scleral band uncovered. Anisocoria was noted and left pupil was dilated and not reacting to light. Passive opening or closure of the left eye did not influence the right lid retraction. The features were consistent with left sided $3^{\text {rd }}$ cranial nerve palsy. On the right side, the eye was tonically deviated downward and could not be elevated voluntarily beyond the horizontal plane. Abduction and adduction seemed normal on the right eye. Vertical oculocephalic eye movements were abolished upward and downward on the left eye and upward only in right eye (Figure 1). Rest of the cranial nerves were within normal limits. Motor examination revealed $4 / 5$ power in right upper and lower limb and sensory examination showed a 50\% decrease in sensation in right half of body compared to the left side. He also had a right sided hemiataxia, dysmetria and dysdiadochokinesia.

We considered a possibility of left $3^{\text {rd }}$ Cranial Nerve affection at nucleus level along with left thalamic involvement. The temporal course of the symptom evolution was favouring a cerebrovascular stroke in the posterior circulation territory. We proceeded with the relevant investigations.

Routine blood investigations were within normal limits. Thyroid profile was also normal. Lipid profile was deranged (Increased, total cholesterol, low density lipoprotein and triglyceride). MRI of brain revealed evidence of left paramedian mesencephalic infarct extending dorsally upto the posterior commissure and left thalamic infarct with diffusion restriction. (Figures 2 and 3) MR Angiography was unremarkable.

Thrombotic profile was non contributory

24 hrs Holter Monitoring did not reveal any evidence of Atrial Fibrillation.

2 D Echocardiography showed left ventricular wall hypokinesia with LVEF of $40 \%$.

Transesophageal Echocardiography did not reveal any Left atrial thrombus.

He is on follow up at present and on dual antiplatelets, statin and antihypertensives. The hypesthesia has improved but there is persistence of mild right hemiataxia and improving ocular problems.

\section{DISCUSSION}

Unilateral ptosis and contralateral eyelid retraction originally described as palpebral plus-minus syndrome by Gaymard et al. ${ }^{1}$
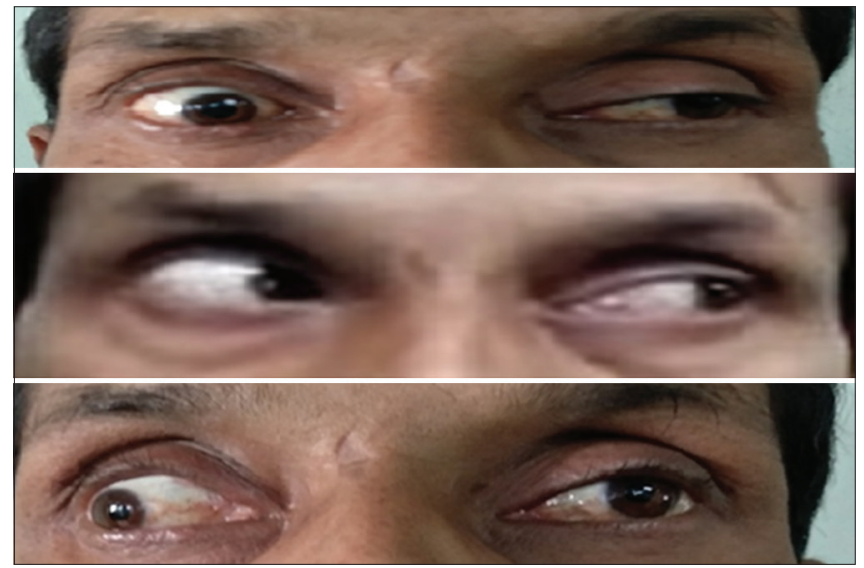

Figure 1: Images taken in primary gaze, left and right gaze showing evidence of ophthalmoplegia with left eye ptosis and right eyelid retraction

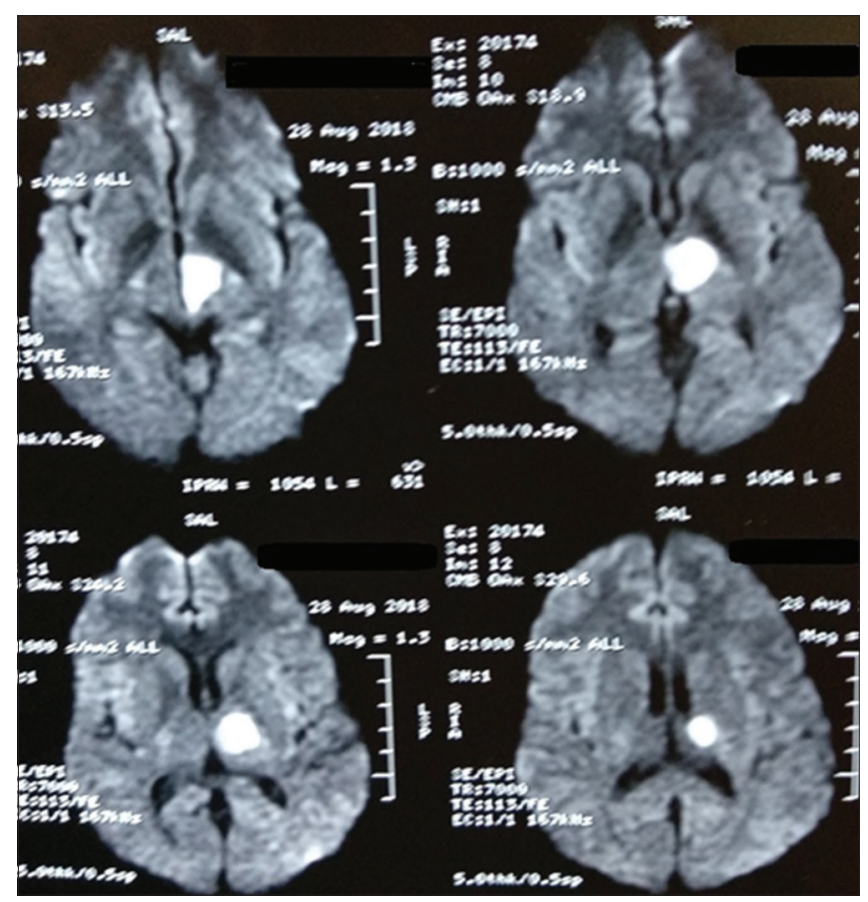

Figure 2: MRI Brain (DWI sequence) showing midbrain and thalamic infarct

Our patient presented an unusual eyelid abnormality, a unilateral ptosis and contralateral superior eyelid retraction, which is called the "plus-minus lid syndrome". ${ }^{1}$ This aspect was present immediately after the onset of stroke. The association of a left oculomotor nerve paralysis with a right superior rectus (SR) paralysis is consistent with a left nuclear oculomotor nerve syndrome. ${ }^{4}$

Two muscles are involved in upper eyelid elevation; the tarsal smooth muscle of Muller that has a role limited to tonic control of eyelid position and the levatorpalpebrae, a skeletal muscle innervated by fascicles of the oculomotor nerve. These fascicles arise from a single medial nucleus 


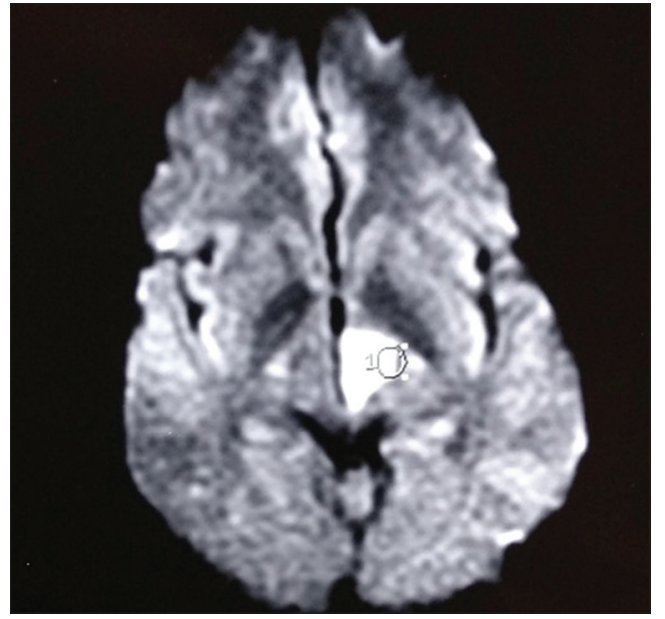

Figure 3: MRI Brain (DWI sequence) showing Left paramedian midbrain infarct

called the central caudal nucleus, a subdivision of the oculomotor nuclear complex. ${ }^{5}$

Nuclear lesions therefore lead to bilateral ptosis; however fascicular lesions can cause unilateral ptosis. Another structure, the nucleus of the posterior commissure provides inhibitory inputs to the central caudal nucleus. Each nucleus of the posterior commissure is connected with its contralateral counterpart through the posterior commissure but does not project directly on the central caudal nucleus. It projects on the levatorpalpebrae motor neurons in the supra oculomotor area, located dorso laterally to the oculomotor nucleus, within the periaqueductal grey mater. ${ }^{5}$

Our patient had a left paramedian infarct in the midbrain resulting in ptosis of the left eye and lid retraction of the right eye. The eyelid retraction was possibly due to failure of inhibition of the contralateral levatorpalpebrae (by the nucleus of the posterior commissure) resulting in its overaction. ${ }^{5}$ It may thus be inferred that inhibitory connections between the nucleus of posterior commissure and the central caudal nucleus (through the supraoculomotor area) are unilateral and crossed. ${ }^{5}$

The ocular malalignment as a manifestation of thalamic skew was refuted as the Vestibulo ocular reflex (VOR) was impaired. The contiguity of the supra occulomotor area and the adjacent third nerve nucleus would explain the coexistence of a "plus-minus lid syndrome" with a nuclear third nerve syndrome. ${ }^{1}$

Our patient had hemiataxia on the right side. This was probably due to concomitant damage to the dentatorubrothalamic projections to the ventral lateral nucleus by a lesion rostral to the decussation of the superior cerebellar peduncle or damage to the ventral lateral nucleus itself results in hemiataxia of contralateral limbs. This is in the thalamogeniculate territory. The MRI of the patient revealed a left thalamic infarct which may have contributed to the right hemiataxia too.

Alsherbini et al in their case of plus minus lid syndrome with ataxia presented a similar scenario in a Caucasian patient without any diffusion restriction in Brain MRI. ${ }^{6}$

Melo TP et al in their case series on thalamic strokes have described the entity of acute hemiataxia-hypesthesia, that may be highly suggestive of strokes involving the lateral part of the thalamus (thalamogeniculate territory). ${ }^{3}$

In our case we present a unique coassociation of two rare syndromes attributable to paramedian mesencephalic and thalamic infarct.

\section{CONCLUSIONS}

Plus-minus lid syndrome with hypesthesiahemiataxia is a rare presentation of midbrain infarction with a simultaneous thalamic infarction. Its unique localization and anatomical description was essential for an appropriate clinicoradiological correlation.

\section{REFERENCES}

1. Gaymard B, Lafitte C, Gelot A and de Toffol B. Plus minus lid syndrome. J Neurol Neurosurg Psychiatry 1992; 55: 846-848 https://doi.org/10.1136/jnnp.55.9.846

2. Porta Etessam J, Benito Leon J, Berbel A and Martinez A. Plus minus lid syndrome without ophthalmoplegia. Eur J Neurol 1999; 6:107.

https://doi.org/10.1046/j.1468-1331.1999.610107.x

3. Melo TP and Bogousslavsky J. Hemiataxia-hypesthesia: a thalamic stroke syndrome. J Neurol Neurosurg Psychiatry 1992; 55:581-584.

https://doi.org/10.1136/jnnp.55.7.581

4. Walsh FB and Hoyt WF. Clinical neuro-ophthalmology vol 2, 4th ed. Baltimore, Williams and Wilkins, 1984:933-995.

5. Gaymard B, Huynh C and Laffont I. Unilateral eyelid retraction. J Neurol Neurosurg Psychiatry 2000;68(3):390-392.

https://doi.org/10.1136/jnnp.68.3.390a

6. Alsherbini K, Kapadia K and Sattin JA. A rare midbrain infarction presenting with plusminus lid syndrome with ataxia: a case report. Journal of Medical Case Reports 2011; 5:525. https://doi.org/10.1186/1752-1947-5-525 


\section{Authors Contribution:}

SG and MKR- Concept and design of the study, reviewed the literature, manuscript preparation and critical revision of the manuscript; GG- Concept, collected data and review of literature and helped in preparing first draft of manuscript; AB and NR- Conceptualized study, literature search, statistically analyzed and interpreted, prepared first draft of manuscript; SN and NA- Concept of study, collected data and review of study.

Work attributed to:

Department of Neurology, Nil Ratan Sircar Medical College and Hospital, Kolkata, West Bengal, India.

Orcid ID:

Dr Sinjan Ghosh- (10 https://orcid.org/0000-0003-2416-3181

Dr Gautam Guha- (D) https://orcid.org/0000-0002-8902-2817

Dr Manoj Kumar Roy- (1) https://orcid.org/0000-0002-4335-6010

Dr Annesh Bhattacharjee- (i) https://orcid.org/0000-0001-6560-2692

Dr Nikhil Repaka- https://orcid.org/0000-0002-3856-8940

Dr Sourav Nanda- https://orcid.org/0000-0003-2049-8208

Dr Niraja Agasti - (iD https://orcid.org/0000-0001-5884-719X 